\title{
Hochöfen der Seele - Furnaces of the Soul
}

\author{
Authors: Jürgen Kanold \\ Submitted: $\quad$ 22. November 2019 \\ Published: $\quad$ 28. November 2019 \\ Volume: 6 \\ Issue: 11 \\ Languages: German \\ Keywords: $\quad$ Alexander Kluge, Artist, Thinker, Director, Exhibition, Ulm \\ Categories: $\quad$ Visual Arts, Architecture and Design \\ DOI: $\quad$ 10.17160/josha.6.11.613
}

\section{Abstract:}

Feuilleton Editor-in-Chief of Ulm's "Südwest Presse", Jürgen Kanold, writes about the remarkable exhibition "Alexander Kluge - die Macht der Musik" in Ulm. Together with Edgar Reitz, Alexander Kluge established the Department of Film at the "Hochschule für Gestaltung (HfG) Ulm", the famous Ulm School of Design. The HfG was a college of design founded in 1953 by Inge Aicher-Scholl, Otl Aicher and Max Bill, the latter being first rector of the school and a former student at the Bauhaus. The current exhibition is supported by the KULTURSTIFTUNG DES BUNDES and resulted from a co-operation of KUNSTHALLE WEISHAUPT and MUSEUM ULM. The exhibition is open until 19th of April, 2020 on Tuesday to Sunday, 11 am to 5 pm, Thursday to 8 pm. (Article appeared in "Südwest Presse" on October 19th, 2019)

\section{JOSHA Jounalos sesmee, Humanities and Arts}




\section{Hochöfen der Seele}

Der 87-jährige Alexander Kluge erzählt in einer großen Ausstellung in der Kunsthalle Weishaupt und im Museum Ulm von der "Macht der Musik"

\section{Von Jürgen Kanold}

Einem Marsmenschen die Oper zu erklären, da würde ich mich schwertun“, sagt Alexander Kluge. Er meint zwar, dass diese um 1600 erfundene Kunstform nun wirklich sehr komplex ist. Aber wenn es einem gelänge, dann diesem 87-jährigen Filmemacher, Schriftsteller, Philosophen - diesem geradezu außerirdischen Meister der Assoziation.

Kluge, dieser große Intellektuelle der Bundesrepublik, der als Justitiar am Frankfurter Institut für Sozialforschung arbeitete und ein Vertrauter Theodor W. Adornos war, hat eine hohe Achtung vor den Theoretikern, aber nur, wenn sie mit der „Herzlichkeit der Vernunft“ arbeiteten. Und so hat der Sohn eines Halberstadter Theaterarztes, der seine ,ersten Fetzen“ Musik mitbekam, als er den Vater zu einer Geburt rufen musste, immer die Oper geliebt, dieses „Kraftwerk der Gefühle“, das von allen „Missverständnissen, Tragödien und Verwurstelungen“ der menschlichen Erfahrung gespeist sei. Die Musik als Gegenpart, als Regulativ in einer von mathematischem Kalkül geprägten Zeit.

Es werden keine Marsmenschen nach Ulm kommen, aber auch jedem irdischen Bewohner sei der Besuch der Kunsthalle Weishaupt und des Museums Ulm empfohlen, wo Alexander Kluge an diesem Sonntag seine Ausstellung „Die Macht der Musik“ eröffnet. Es geht um die Oper, den „Tempel der Ernsthaftigkeit“. Man darf sich freilich nicht vornehmen, das jetzt alles schnell begreifen zu wollen: Allein gut 20 Stunden Film laufen auf Video-Schirmen oder Projektionen und gerne in synchroner Flut, dialektisch geschnitten. Dazu Texte, Kunst. Der Besucher muss das vernetzen. Schon die sinnliche Erfahrung ist ein Erlebnis. Es vergeht einem nicht Hören und Sehen, man wird dazu animiert.

Kluge montiert: sein eigenes filmisches Material mit Arbeiten anderer Künstler. Auch Dialoge, Konfrontationen bietet diese unfassbar vielfältige Ausstellung, diese Wunderkammer der 
Geistesgeschichte; Katharina Grosse etwa hat extra Installationen beigesteuert. Die Stationen heißen „Hochöfen der Seele“, „Wenn die Oper sachlich wäre“, „Lamenti“ oder „Oper und Bombenkrieg“. Es geht um das Schicksal der Frauen oder „die Entstehung der Schönen aus dem Leid“.

Was Kluge beweisen will in der heutigen Welt der Algorithmen: „Ohne Musik wäre alles Leben ein Irrtum“ - sagt er, sagte so ähnlich Friedrich Nietzsche. Was aber, typisch Kluge, beeindruckt: Neben der „Hochkunst“ steht die „Bodenhaftigkeit“. Immer gibt es den „Antibegriff“. Er würde, erzählt Kluge, diesen Verrat an den Kurden in Syrien durch die Amerikaner, den Angriff auf sie durch die Türken, nicht aushalten, wenn es nicht auch die Groteske gäbe in dieser Welt - und zum Beispiel Helge Schneider. Mit diesem Spaßmacher des Irrsinns führte Kluge ein Interview: „Der Opernsänger im Stummfilm“. Helge Schneider spielt den Opernkasper, spricht wild gestikulierend - aber ohne Ton. Lustig.

Warum Ulm? Kluge, der 1962 mit anderen jungen Filmemachern im Oberhausener Manifest „Papas Kino“ für tot erklärt hatte, gründete im selben Jahr an der Hochschule für Gestaltung (Hfg) mit Edgar Reitz die Filmabteilung. Mit Hannelore Hoger in der Hauptrolle, die am Ulmer Theater ihre Karriere begonnen hatte, gewann Kluge für seinen Spielfilm „Die Artisten in der Zirkuskuppel: ratlos“ 1968 den Goldenen Löwen in Venedig. Die Schauspielerin, dem TVPublikum als Kommissarin Bella Block bekannt, ist in der Ausstellung vielfach in aktuellen Projektionen zu sehen. Wie Kluge überhaupt für die Ausstellung unglaublich viel Neues geschaffen hat. Und für seine Sendeformate im Privatfernsehen seit 1988 drehte er mehr als 20 Jahre im Ulmer Theater für seine Kulturmagazine und seine Sendung „Die Stunde der Filmemacher".

Kluge versteht sich als Stachel im Fleisch der Kulturindustrie und als Patriot eines Kinos vor der Kommerzialisierung. Damit ist diese Ausstellung auch eine Heimkehr - mit Leidenschaft und erheblichem Aufwand inszeniert und von überregionaler Bedeutung. Stationen im Museum Ulm erzählen Ulmer Theatergeschichte. Wenn etwa ein kaum 20-jähriger Korrepetitor im Bild erscheint und Operette spielt - Philippe Jordan, heute Musikchef in Paris und bald der Wiener Staatsoper. Wobei in der Kunsthalle Weishaupt auch Teile des Bühnenbildes für Marc Andrés Stuttgarter Opern-Uraufführung „Wunderzaichen“ groß aufgebaut sind. 
An dieser Stelle kapituliert der Rezensent, der nur einen Bruchteil des in Ulm ausgebreiteten Kluge-Kosmos schildern kann - und geht wieder in die faszinierende Ausstellung.

(Der Artikel ist am 10. Oktober 2019 in der Südwest Presse Ulm erschienen und für Abonnenten zugänglich unter www.swp.de. JOSHA dankt für die freundliche Genehmigung der Nachveröffentlichung.) 